\title{
SISTEM INFORMASI PENGELOLAAN TRANSPORTASI PENGIRIMAN BBM PADA PT. RATAH INDAH SAMARINDA
}

\author{
Ahmad Rofiq Hakim ${ }^{1)}$, Amelia Yusnita ${ }^{2)}$, Elys Diawati $^{3)}$ \\ ${ }^{1,2}$ Sistem Informasi, Stmik Widya Cipta Dharma \\ ${ }^{3}$ Sistem Informasi, Stmik Widya Cipta Dharma \\ $1,2,3$ Jl. Prof. M. Yamin No. 25, Samarinda, 75123 \\ E-mail : informatikawicida@gmail.com ${ }^{1)}$, qonita23@yahoo.com ${ }^{2}$, rakezzakaw@yahoo.com ${ }^{3)}$
}

\begin{abstract}
ABSTRAK
Sistem Informasi Pengelolaan Transportasi Pengiriman BBM merupakan sistem yang dibangun untuk proses pengiriman BBM berupa input data BBM, data konsumen, data distributor, transaksi pemasukkan BBM dan transaksi pengiriman BBM serta pelaporannya.

Penelitian ini dilakukan pada PT. Ratah Indah Samarinda yang beralokasi di Samarinda dengan menggunakan metode penelitian yaitu metode pengumpulan data, studi lapangan, studi pustaka, analisis kebutuhan, desain sistem, dan implementasi sistem.

Pada penelitian ini telah dibuat Sistem Informasi Pengelolaan Transportasi Pengiriman BBM dengan desain sistem mengunakan Flow Of Document (FOD), Data Flow Diagram (DFD) dan Hirachy Plus Input Process Output (HIPO). Metode pengembangan sistem yang digunakan yaitu SDLC dan metode pengujian menggunakan Black Box. Aplikasi Ini dibangun menggunakan software yaitu Bahasa Pemrograman Visual Basic 6.0, database yang digunakan Microsoft Access 2007. Sistem yang dibangun beroperasi pada Sistem Operasi Windows.

Dari hasil implementasi sistem, disimpulkan bahwa dengan penggunaan software dapat membantu dalam proses pengiriman BBM pada PT. Ratah Indah Samarinda. Serta penulis memberikan saran agar PT. Ratah Indah Samarinda membuat koneksi jaringan komputer ke masing-masing bagian untuk memudahkan pengolahan data.
\end{abstract}

Kata Kunci : Sistem Inforamsi, Pengiriman, BBM

\section{PENDAHULUAN}

Dewasa ini Komputer merupakan salah satu hal terpenting dalam menyelesaikan suatu pekerjaan pengolahan data diberbagai bidang pekerjaan, baik itu kantor pemerintahan maupun kantor - kantor milik swasta. Hal ini tidak dapat dipungkiri lagi sebab tanpa menggunakan komputer dalam menyelesaikan suatu pekerjaan pengolahan data akan mempersulit dan memerlukan waktu yang cukup lama dalam penyelesaiannya. Tanpa menggunakan komputer kita sering dihadapkan pada beberapa masalah yang sulit diselesaikan dengan cara manual.

Pengelolaan transportasi pengiriman BBM jenis solar dan bensin merupakan suatu proses pendataan yang menggambarkan transaksi masuk dan keluarnya BBM jenis solar dan bensin seperti mendata distributor dan konsumen yang dalam hal ini dikhususkan didaerah hulu.

Pada kantor PT. Ratah Indah Samarinda proses transaksi pemasukkan dan pengiriman BBM jenis solar dan bensin dilakukan setiap hari dimana sering tidak terdatanya berapa BBM yang masuk dan berapa BBM yang telah terkirim setiap harinya. Sistem yang berjalan saat ini masih sangat manual dimana pengolahan data transaksi pemasukkan dan pengiriman BBM hanya dicatatan dalam sebuah buku besar yang tidak efektif dan efesien.

Pada skripsi ini penulis membuat suatu sistem informasi dengan menggunakan Visual Basic 6.0 yang dapat memudahkan untuk mengelola transportasi pengiriman BBM pada PT. Ratah Indah Samarinda.

\section{RUANG LINGKUP PENELITIAN}

Dalam penelitian ini permasalahan mencakup : 
1. Cakupan Masalah

2. Pada kantor PT. Ratah Indah Samarinda proses transaksi pemasukkan dan pengiriman BBM jenis solar dan bensin dilakukan setiap hari dimana sering tidak terdatanya berapa BBM yang masuk dan berapa BBM yang telah terkirim setiap harinya. Sistem yang berjalan saat ini masih sangat manual dimana pengolahan data transaksi pemasukkan dan pengiriman BBM hanya dicatatan dalam sebuah buku besar yang tidak efektif dan efesien.Batsan-batasan penelitian

3. Rencana hasil yang didapatkan

1). Sistem Informasi Pengelolaan Transportasi Pengiriman BBM pada PT. Ratah Indah Samarinda secara cepat dibandingkan dengan sistem yang ada. Dengan begitu kinerjanya dapat diwujudkan secara maksimal.

2). Membantu kerja PT. Ratah Indah Samarinda, khususnya dalam hal Pengelolaan Transportasi Pengiriman BBM. Dan dapat menambah wawasan dan pengetahuan tentang penggunaan sistem informasi.

3). Membuat Sistem Informasi pengelolaan transportasi pengiriman BBM menjadi terkomputerisasi

4). Membuat basisdata transaksi pengiriman BBM.

\section{BAHAN DAN METODE}

\subsection{Penjelasan Bahan}

Menurut Agus (2003), Sistem adalah koleksi dari elemen-elemen seperti manusia, Sumber daya, prosedurprosedur yang diharapkan untuk melakukan indetiafiable fuction atau melayani satu tujuan.

Microsoft Access Robin (2005) adalah sebuah software produksi dari Microsoft. Microsoft Access sebelumnya sudah memiliki banyak versi sebelum versi Microsoft Access 2003. Microsoft Acces merupakan bagian dari Office, dimana didalamnya terdapat beberapa software lain seperti Microsoft Word, Microsoft Excel, dan lain-lain. Microsoft acces merupakan software yang berfungsi untuk pengembangan aplikasi database. Khususnya aplikasi database berskala kecil sampai menengah.

Menurut LPKBM Madcoms Madiun ( 2001) Visual Basic pada dasarnya adalah sebuah bahasa pemrograman komputer. Bahasa pemrograman adalah perintah-perintah atau instruksi yang dimengerti oleh komputer untuk melakukan tugas-tugas tertentu.

3.2 Metode

Model Air Terjun (Waterfall) adalah untuk membantu mengatasi kerumitan yang terjadi akibat proyek-proyek pengembangan perangkat lunak (Simarmata, 2010).

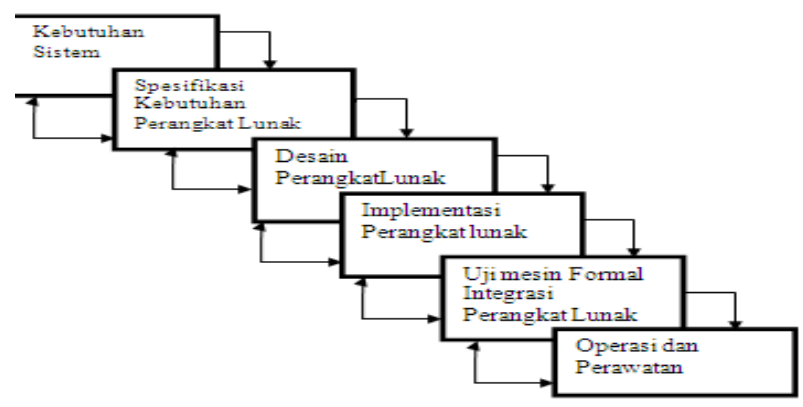

Gambar 1. Model Pengembangan Air Terjun

\section{RANCANGAN SISTEM/APLIKASI}

1. Flow Of Document (FOD) Yang Berjalan

Dari Flow Of Document yang sedang berjalan bahwa Sistem Informasi Pengelolaan Transportasi Pengiriman BBM dimulai dari administrasi menerima data BBM dari distributor yang kemudian menginputkan data BBM dengan cara manual seperti, pemberian harga. Kemudian proses pemesanan BBM yang diberikan konsumen kepada administrasi untuk melakukan proses transaksi pengiriman BBM yang menghasilkan nota pengiriman 2 rangkap yang akan diberikan pada konsumen dan sebagai arsip. Kemudian untuk proses pembuatan laporan dikerjakan oleh administrasi, menghasilkan laporan daftar BBM dan laporan pengiriman BBM yang masing-masing dibuat 2 rangkap, rangkap pertama sebagai arsip, sedangkan rangkap kedua diberikan kepada pimpinan untuk mengetahui perkembangan perusahaan. Laporan yang diterima oleh entitas pimpinan meliputi laporan daftar BBM dan laporan pengiriman BBM. Proses selesai pada entitas pimpinan. 


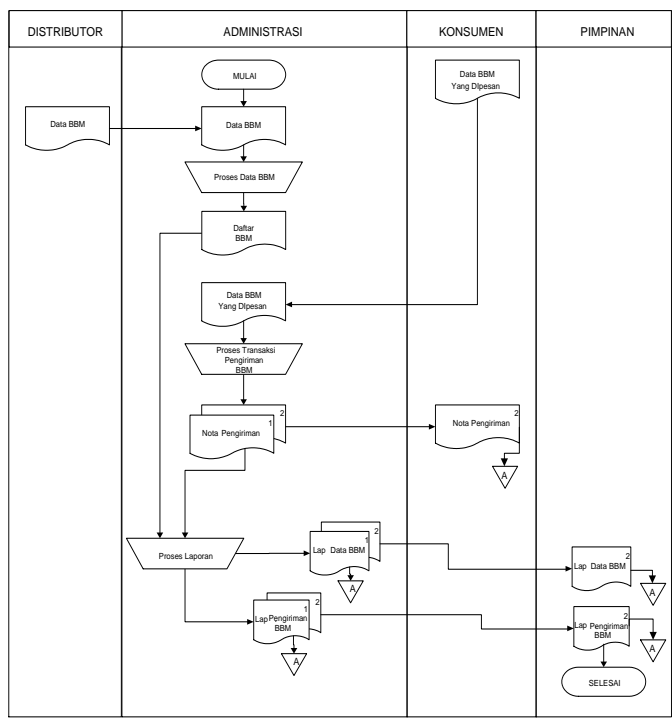

Gambar 2. FOD Yang Berjalan

2. Fflow Of Document (FOD) Yang Diusulkan

Sistem Informasi Pengelolaan Transportasi Pengiriman BBM dimulai dari BBM yang telah dipesan sebelumnya kepada distributor. Lalu dilakukan proses pemasukkan BBM yang dipesan. Kemudian di berikan kepada administrasi untuk di input secara komputerisasi ke dalam database BBM masuk. Kemudian diteruskan untuk pembuatan laporan. Berawal saat konsumen telah mengambil BBM yang diinginkan, yang akan diberikan kepada administrasi untuk melakukan transaksi pengiriman BBM yang secara otomatis akan tersimpan pada tabel pengiriman BBM kemudian dialirkan ke proses pembuatan laporan. Hasil dari transaksi pengiriman BBM tersebut adalah dua rangkap nota pengiriman, yang pertama diberikan kepada konsumen serta BBM yang telah dibelinya. Lalu nota pengiriman yang kedua diberikan kepada administrasi sebagai arsip. Yang kemudian dapat dikelola oleh administrasi menjadi laporan yang dibutuhkan. Yang kemudian diserahkan kepada pimpinan dan sebagai arsip. Pada entitas administrasi juga terdapat dokumen data BBM kemudian dinput lewat keyboard lalu diproses secara komputerisasi yang tersimpan dalam database data BBM dan terbitlah dokumen daftar BBM yang kemudian dialirkan ke proses pembuatan laporan. Entitas distributor juga memberikan data distributor ke entitas administrasi kemudian diinput lewat keyboard lalu diproses secara komputerisasi dan disimpan dalam database distributor. Pada entitas konsumen juga memberikan data konsumen ke entitas administrasi lalu diinput lewat keyboard dan diproses secara komputerisasi yang tersimpan dalam database konsumen sehingga terbitlah daftar konsumen dan dialirkan ke proses pembuatan laporan. Laporannya meliputi daftar BBM, daftar distributor, daftar konsumen, laporan pemasukkan BBM dan laporan pengiriman BBM. Proses berakhir pada entitas pimpinan.

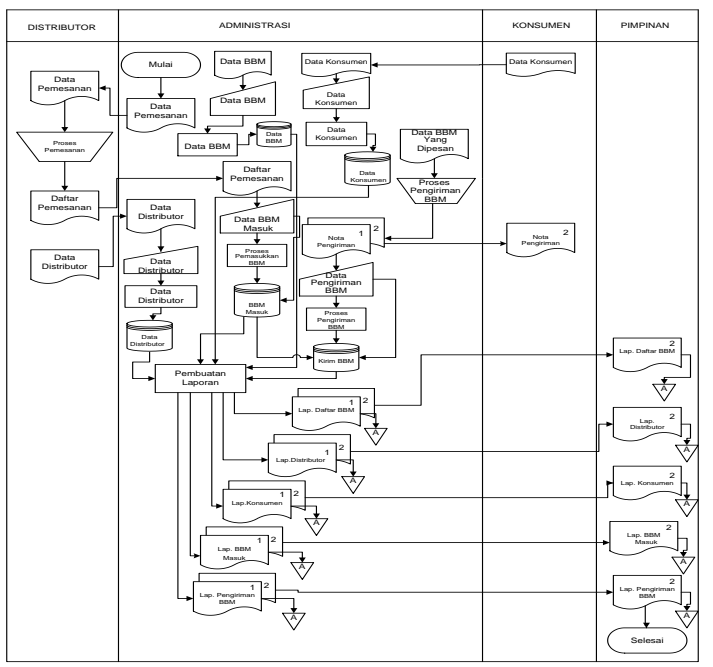

Gambar 3. FOD Yang Diusulkan

\section{Context Diagram}

Terdapat empat kesatuan luar (eksternal entity) yaitu bagian Administrasi sebagai menginputkan data BBM, data BBM masuk kepada sistem dan dari sistem memberikan daftar BBM, daftar distributor, daftar konsumen, laporan BBM masuk, laporan pengiriman BBM dan nota pengiriman ke entitas Administrasi. Entitas Distributor memberikan data distributor ke sistem dan dari sistem memberikan data pemesanan ke entitas distributor. Entitas konsumen memberikan data konsumen ke sistem dan dari sistem memberikan Nota pengiriman BBM ke entitas konsumen. Entitas Pimpinan mendapat laporan dari sistem berupa daftar BBM, daftar distributor, daftar konsumen, laporan pemasukkan BBM dan laporan pengiriman BBM. 


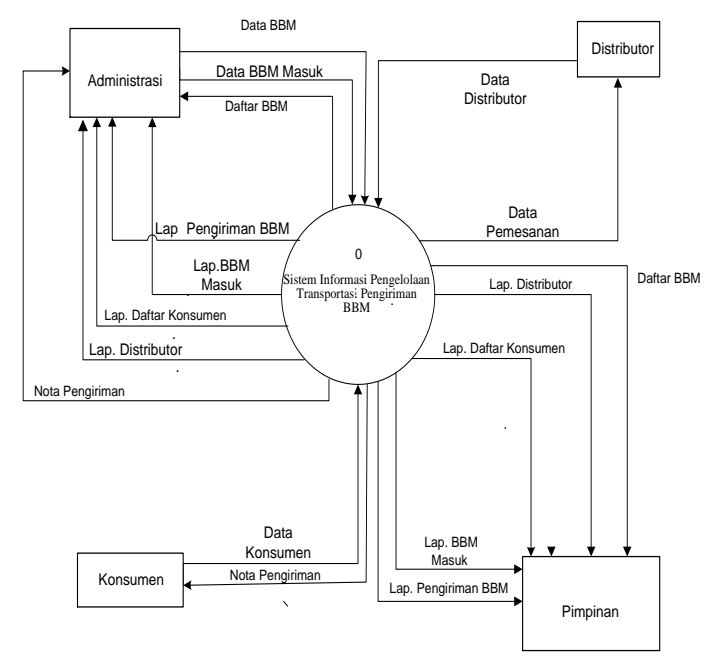

Gambar 4. Context Diagram

\section{Data Flow Diagram (DFD) Level 0}

Entitas Administrasi menjadi sumber data BBM masuk yang datanya disimpan dalam penyimpanan data (data store) BBM masuk dan juga Entitas Administrasi menjadi sumber data BBM yang datanya disimpan dalam penyimpanan data (data store) BBM. Entitas Distributor menjadi sumber data distributor yang datanya disimpan dalam penyimpanan data (data store) disributor. Entitas Bagian Konsumen menjadi sumber data konsumen yang datanya disimpan dalam penyimpanan data(data store) konsumen entitas konsumen juga memperoleh nota pengiriman dari proses pengiriman bbm. Proses pembuatan laporan memperoleh data dari data store $\mathrm{BBM}$, data store distributor, data store konsumen, data store BBM masuk dan data store pengiriman BBM dimana menghasilkan laporan daftar BBM, daftar distributor, daftar konsumen, laporan BBM masuk dan laporan pengiriman BBM yang dialirkan ke entitas Pimpinan dan Administrasi.

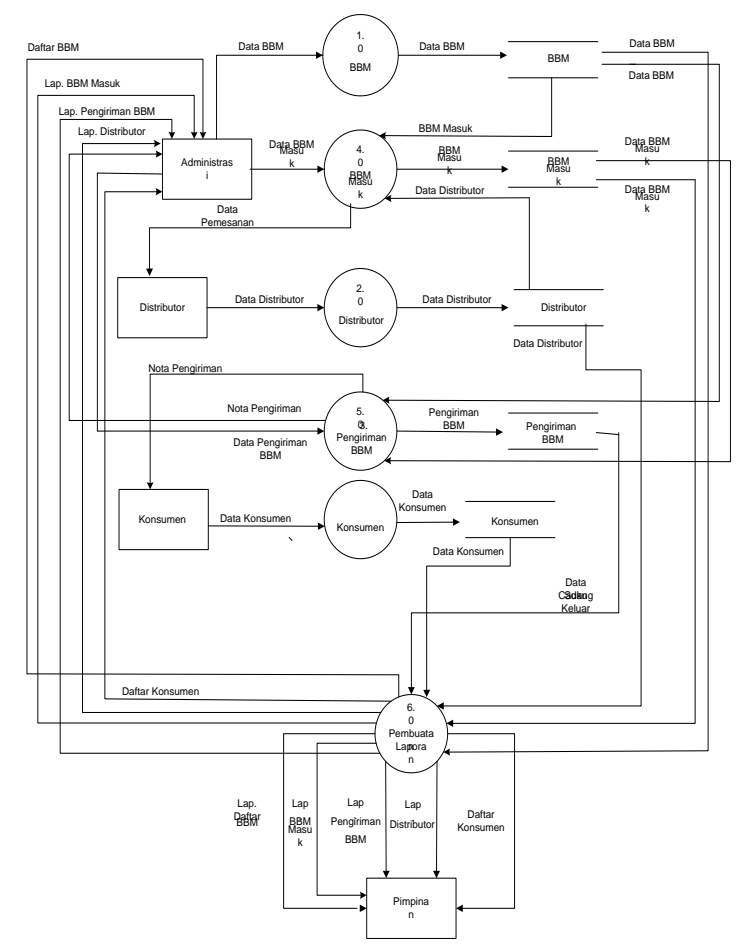

Gambar 5. Data Flow Diagram (DFD) Level 0

\section{Data Flow Diagram (DFD) Level 1}

DFD level 1 pada (gambar 4.6) dimulai dari data store BBM mengalirkan data BBM ke proses laporan daftar $\mathrm{BBM}$, proses laporan BBM masuk dan proses laporan pengiriman BBM. Data store BBM masuk yang dialirkan ke proses laporan $B B M$ masuk. Data store pengiriman BBM mengalirkan data pengiriman BBM ke proses laporan pengiriman BBM. Data store distributor mengalirkan data distributor ke proses laporan distributor. Data store konsumen mengalirkan data konsumen ke proses laporan konsumen. Dari proses tersebut menghasilkan laporan daftar BBM, daftar distributor, daftar konsumen, laporan BBM masuk dan laporan pengiriman $\mathrm{BBM}$ yang kemudian dialirkan ke entitas pimpinan.

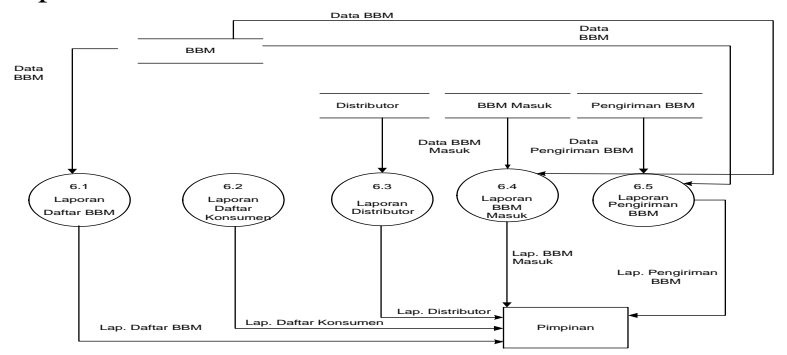

Gambar 6. Data Flow Diagram (DFD) Level 1 


\section{IMPLEMENTASI}

1. Tampilan Form Input Data BBM

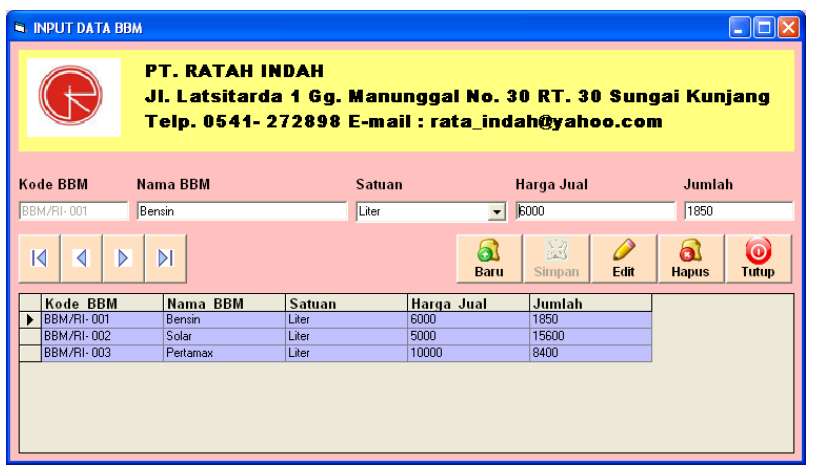

Gambar 7. Form Input Data BBM

Pada gambar 7. merupakan form untuk menginputkan data BBM. Data yang akan diinput berisikan kode BBM, nama BBM, satuan, harga jual dan jumlah. Dalam tampilan input data ini terdapat 4 (empat) tombol navigasi dan 5 (lima) tombol lainnya yaitu tombol baru, simpan, edit, hapus dan tutup.

\section{Tampilan Form Input Data Distributor}

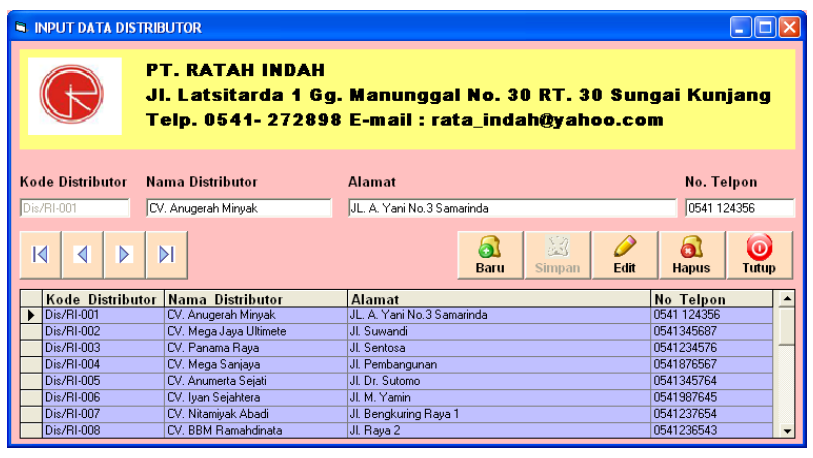

Gambar 8. Form Input Data Distributor

Seperti yang terlihat pada gambar 8. form untuk menginputkan data distributor. Data yang akan diinput berisikan kode distributor, nama distributor, alamat dan no telpon. Tampilan Form Input Data Konsumen

\section{Tampilan Form Data Konsumen}

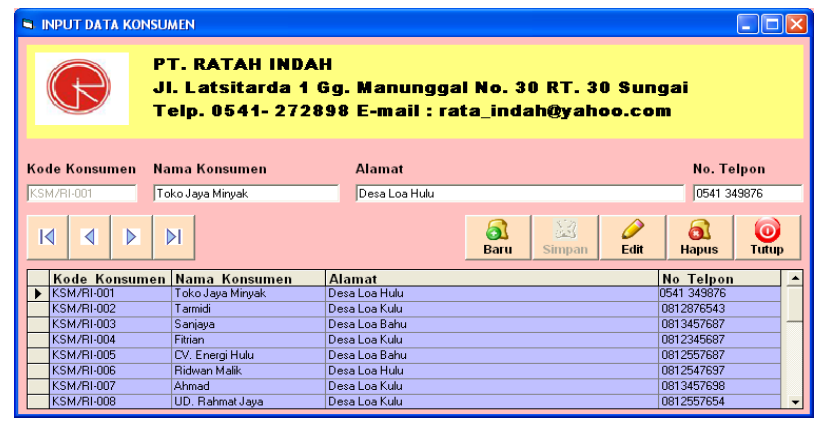

Gambar 9. Form Input konsumen
Seperti yang terlihat pada gambar 9, form input data konsumen berupa kode konsumen, nama, alamat dan telepon.

\section{Tampilan form data pengangkut BBM}

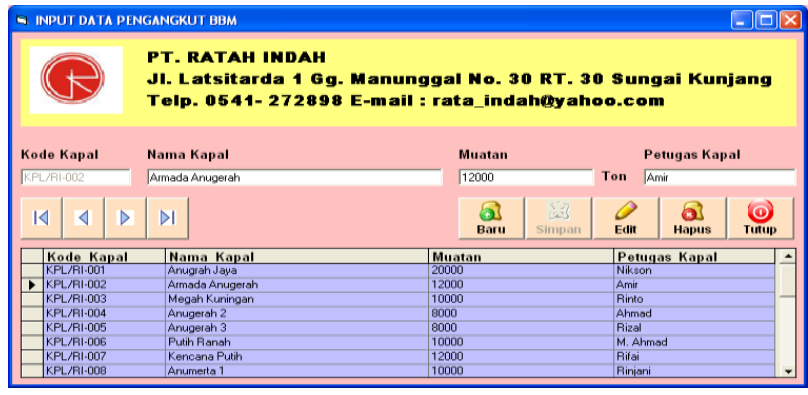

Gambar 10. Form Data Pengangkut BBM

5. Tampilan Form transaksi pemasukan BBM

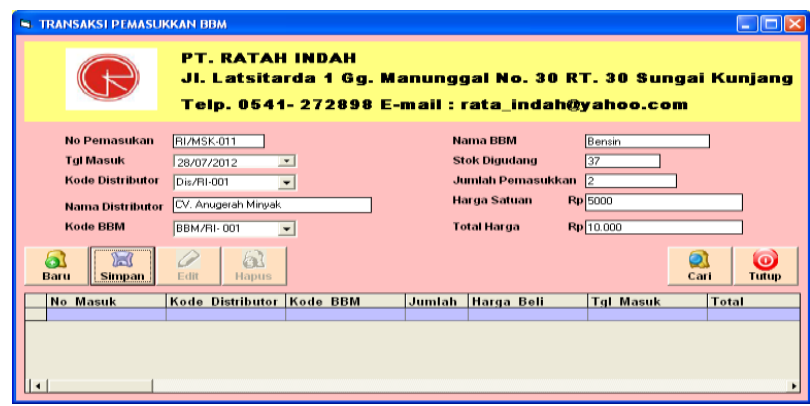

Gambar 11. Form Transaksi Pemasukan BBM Seperti yang terlihat pada gambar 11, form Input Pemesanan digunakan untuk menginputkan data pemesanan suku cadang berupa no purchase order, tanggal, supplier, dan kode permintaan.

\section{Tampilan Form Pengiriman Barang}

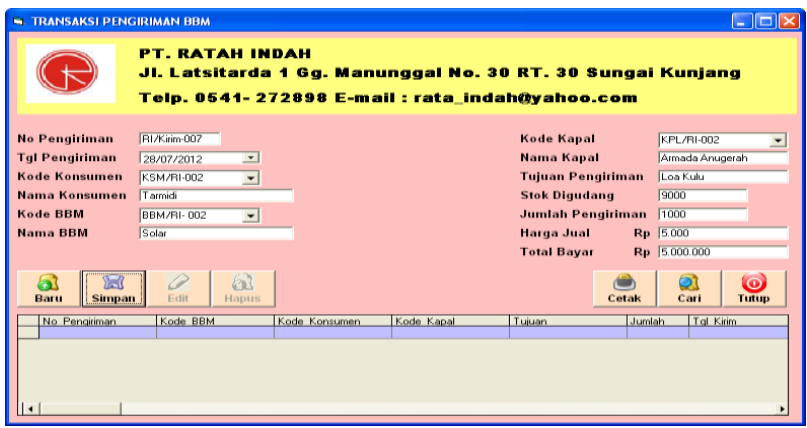

Gambar 12. Form Pengiriman Barang Seperti yang terlihat pada gambar 12, form pengiriman barang digunakan untuk menginput no. pengiriman, tgl pengiriman 
7. Tampilan Grafik Pengiriman BBM Perbulan

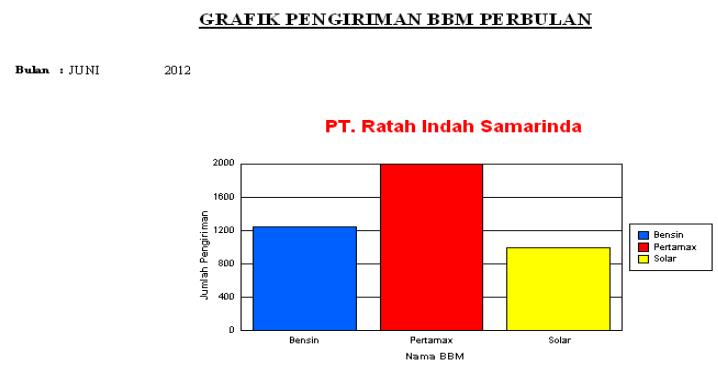

Gambar 12. Form Pengiriman Barang

merupakan tampilan grafik pengiriman BBM perbulan. Informasi yang diberikan meliputi nama bbm, jumlah, tahun dan bulan. Hasil ini didapat dari form transaksi pengiriman BBM.

\section{KESIMPULAN}

1. Dengan adanya Sistem Informasi Pengelolaan Transportasi Pengiriman BBM pada PT. Ratah Indah Samarinda dengan menggunakan pemrograman visual basic 6.0 yang penulis coba terapkan, sangat membantu dalam proses pengolahan data transportasi pengiriman BBM serta pelaporannya.

2. Sistem yang telah dibangun dapat menampikan laporan daftar BBM, daftar konsumen, daftar, distributor, daftar pengangkut BBM, laporan pemasukkan BBM dan laporan pengiriman BBM secara keseluruhan maupun bulanan.

\section{SARAN}

1. agar kedepannya sistem ini dapat dikembangkan dengan menggunakan database mysql atau sql server.

2. Agar sistem ini kedepannya juga dapat dikembangkan dengan menggunakan pemrograman java atau berbasis web site.

3. Agar sistem ini dapat digunakan dalam jangka waktu yang lama dimana sistem ini kedepannya dapat dikembangkan berbasis client server.

\section{DAFTAR PUSTAKA}

Agus, 2003, Sistem Informasi Manajemen terjemahan Hendra Teguh Edisi ketujuh, penerbit Buana Ilmu Komputer, Jakarta.

Gordon B. Davis, 2001, Pengantar Sistem Informasi Manajemen, Andi Yogyakarta, Yogyakarta
Jogiyanto.HM, 2003, Analisis dan Desain Sistem Informasi, Andi Yogyakarta, Yogyakarta

Kamus Besar Bahasa Indonesia, 2001, Edisi Ketiga

Kristanto, 2003, Pengantar Sistem Informasi Manajemen, Andi Yogyakarta, Yogyakarta

LPKBM Madcoms Madiun, 2001, Seri Panduan Pemrograman Microsoft Visual Basic 6.0, Andi Yogyakarta, Yogyakarta

Margono, 2002, Sistem Informasi Manajemen terjemahan Hendra Teguh Edisi ketujuh, penerbit Buana Ilmu Komputer, Jakarta.

Mcleod Raymon, 2001, Sistem Informasi Manajemen terjemahan Hendra Teguh Edisi ketujuh, penerbit Buana Ilmu Komputer, Jakarta.

Teguh, 2001, Sistem Informasi Manajemen terjemahan Hendra Teguh Edisi ketujuh, penerbit Buana Ilmu Komputer, Jakarta. 